\title{
Teaching Behavioral Science to Business Students through Films
}

\author{
Ozgur Ates ${ }^{1}$ \\ ${ }^{1}$ Ankara University, Turkey \\ Correspondence: Ozgur Ates, Ankara University, Turkey. E-mail: ates@politics.ankara.edu.tr
}

$\begin{aligned} & \text { Received: April 9, } 2013 \quad \text { Accepted: July 5, } 2013 \quad \text { Online Published: September 29, } 2013 \\ & \text { doi:10.5539/ass.v9n13p305 }\end{aligned}$ URL: http://dx.doi.org/10.5539/ass.v9n13p305

\begin{abstract}
Films have been used as a supplementary instructional tool in various disciplines in higher education. Research indicates that showing films in the classroom has improved the quality, efficiency and effectiveness of the course. The objective of this study is to show the impact and outcomes of showing films to teach behavioral science to business students. The study was conducted at a university in Turkey to understand the students' retention level of learning the concepts and theories as well as the complexity of human behavior. The data was collected through a survey and classroom observations. The findings show that the students' preferred the integration of films to the course compared to a traditional only lecture course. The class discussions after the screening of the movies also contributed to their retention and helped build critical thinking skills.
\end{abstract}

Keywords: business education, use of films, behavioral science course, retention, critical thinking, Turkey

\section{Introduction}

The 21st century is an era where most of the students have grown up with the Internet, video games, television and movies as central parts of their lives and therefore expect the utilization of technology in the classroom (Parker, 2009). The growth of DVD technology, LCD projectors and other technology now permit large-screen, clear freeze frame images that greatly enhance educators, opportunities to foster visual discrimination skills (Considine \& Baker, 2006). For many years films have been used as a supplementary instructional tool in various disciplines in classrooms. Use of visual stimuli is very valuable in education and as a result integrating films into the classrooms give educators the opportunity to supplement and enhance their teaching and the not so easy theoretical concepts to be better understood by their students. The practice of using film to enhance university level education to enhance teaching techniques is used in many countries (Anwary, 2003; Brown, 2011; Johnston, 2001).

Students easily get distracted in class and instructors have to deal with students that are technologically more competent than they are. Students today grow up with computers and television as an important aspect of their everyday life (Hunt, 2001). Gioia and Brass (1985) state that the younger generation particularly uses imagery to understand the world and many students cognitively engage in television. The use of film in a classroom helps the students to understand concepts in a contextual setting which gives them the opportunity to use critical thinking much more than when using only textbooks (Bluestone, 2000). Showing films and TV shows in the classroom that are popular among students may improve their understanding of theories that are hard to conceptualize in business areas such as customer service, professionalism in meetings or leadership techniques (Parker, 2009). It is important to consider that students enjoy watching films because of the popularity of the medium in the current culture. Smith (2009) noted that he would hear more active discussions of his students in his organizational behavior class about current events, music, sports and movies rather than discussions about recent books or articles they read.

Using film in the classroom as a supplementary instructional tool has been recognized by scholars in many disciplines as an effective teaching method for years. (Atherton, 2013; Chang \& Cryer, 2009; Engert \& Spencer, 2009; Gregg, Hosley, Weng \& Montemayor, 1995; Paddock, Terranova \& Giles, 2001; Tognozzi, 2010). This particular format of teaching undergraduate students through feature films has been used in courses on Introductory Social Psychology, Political Sociology, Family, Social Stratification, Collective Behavior and Mass Communications (Smith, 1982). A study carried by Smith (1982) that began in 1968, suggests that teaching undergraduate sociology course through feature films has improved the quality, efficiency, and effectiveness of the course. The results indicate that the students whose sociology class was supplemented by movies scored as 
well as the students that did not watch a film in their sociology class on acquiring information but scored higher on interest in the course, interest in the discipline and additional sociology courses and lower absenteeism from class meetings (Smith, 1982). One of the important facts of using films for sociology was because the films relatedly portrayed many of the basic sociological concepts. The use of films in teaching psychology has also been an effective tool to demonstrate the difficult to teach concepts (Higgins \& Dermer, 2001). Gregg's et al., (1995) study on teaching psychology through films, reflect that using films were useful since they place psychological concepts and theories into a context that students can relate to their real life experiences.

One of the most important and praised advantages of teaching through films is the ability of film to stimulate discussion and thinking on the part of the students. Films, together with an analysis and a follow up discussion in class, offers a ground for active learning that leads to greater comprehension and recall of learning objectives (Rubin \& Hebert, 1998). Harper and Rogers (1999) in their study note that films can dramatize and expand theoretical issues in ways that clarify and promote discussion. Films also help students to understand the true nature and complexity of human behavior and human conditions. During the period of rapid globalization, films help students to see the connection of structure, culture and the world in transition (Anwary, 2003). Smith (2009) states that it is important to try to use a medium that best allows students to learn, retain, and apply the material, and teaching films as a teaching tool is most suitable. Film is a powerful tool that enables the students to understand human interactions and therefore illustrates concepts and demonstrates the application of theory (Smith, 2009).

Brown (2011) states although films are rich and impactful resources for teaching it is still not widely used as one of the instructional tools. Films reach out to students in many different ways. He states that films offer a different form of text and level than the common written word. Hooks (2008) notes that she realized her students learned more about race, sex, and class from movies than from her theoretical English literature class that she urged the students to read articles and books.

Baccarani and Brunetti (2002) state that business education benefit from film as well, that movies have particularly good potential in teaching students management subjects as the content and method of film provide instructors a useful aid in reaching certain educational goals. There is a gap of literature in the management field whereby feature films were used as the primary instructional medium. Smith's (2009) study is the only study where he has developed an experimental approach to teach an organizational behavior course using film as the primary instructional medium and proves very positive approach. At Smith's organizational behavior class there were no textbooks assigned but rather 46 films and ten articles as course material.

This study aims to bridge the gap in the literature of using films in a behavioral science management course where films are incorporated as the primary instructional medium and discuss the approach in terms of the students' learning the theories and concepts. This study is based on the findings of a behavioral science course offered to business administration students in spring 2012. At the end of the semester the students were asked to complete a survey voluntarily to evaluate the method of teaching through movies for their behavioral science course.

\section{Background of the Films}

Choosing to use films for the behavioral sciences class was to show the aspects of everyday life that was represented in the dramas. Brown (2011) states in dramas, the viewer identifies himself/herself with the character or characters and reacts to the situation. Dramas enable the viewer to enter a different world where they can identify themselves with the character and empathize with the situation or dilemma they are in. "Dramas present another's life like situations, and this process opens up questioning: Why did he/she do that? What are the conditions that provide the environment for his situation? How else might he/she responded? The viewer like the character needs to make choices and the role of the instructor is use questioning to draw the students eyes to the detail, the story, character, context and the choices" (Brown, 2011, p. 236). The students themselves examine their own perspectives and reactions, and become re-tellers not just passive receivers (Nussbaum, 1997). While watching a film the viewer goes through an "empathetic identification" with the character to help us imagine how to handle a difficult choice emotionally (Brown, 2011, p. 236). The power of a movie rests, in part, in the values, the emotional commitments, that they draw upon, affirm or challenge. They articulate strongly about what we value, fear as well as what inspire us (Ganz, 2006).

Behavioral science in management aims to teach the human action and seeks to generalize about human behavior in society. It deals with the core disciplines of psychology, sociology and anthropology where these disciplines are concerned with human behavior. Behavior is a mental process that includes all human activities (moral, cognitive \& emotional) and their reaction and responses to the environmental stimuli which can be observed. 
Throughout the course, forming and changing attitudes, the consistency between attitudes and behaviors, aggression, developing and resolving conflict, prejudice and stereotypes, social influence and the dynamics of groups are discussed.

The intention of using movies is to help students examine important concepts and theories of behavioral science through the film and in doing so develop a critical perspective on those issues. The attempt is to create a process of mutual inquiry where the role of the instructor is to facilitate a dialogue in which students can learn from each other and from themselves by reflecting upon their beliefs and cultural background.

The behavioral science course is a weekly three hour must course offered in the spring semester for freshmen business administration students. One hundred and sixteen students enrolled in the course. Three movies were screened. The first one, Das Experiment is based on Dr. Philip Zimbardo's, "The Stanford Prison Experiment" that was a study of psychological effects of becoming a prisoner or prison guard, that was conducted at Stanford University from August 14-20, 1971. Although twenty four male students were randomly assigned to take on the roles of prisoners and guard in a mock prison, the participants adopted to their roles beyond expectations. The movie was particularly chosen to show the experimental research methodology, how it was designed, the control group and validity as well as the human behavior under such circumstances.

The second movie is American History X, the story of two brothers, both intelligent and charismatic students, drawn into the neo Nazi movement becoming white supremacists. The movie focuses on how they become racist as well as how they change their prejudices over time and their confrontation. Racism is a strong prejudice that is known to develop mainly in childhood and is hard to change. The movie shows how humans attain an attitude and how it becomes human behavior.

The third movie is Crash, a film about racial and social tensions in Los Angeles, California. The film rather than separating the characters into victims and offenders, show the victims of racism are often shown to be racist themselves in different contexts and situations. The racist remarks and actions are shown to stem from ignorance and misconception rather than a malicious personality. It shows the historically embedded inequalities that continue to affect different racial groups.

For the screenings no Turkish movies were particularly chosen although there are a number of movies close to the content of American History X and Crash that are about prejudices and social tensions and clashes. These issues are somewhat politically sensitive and discussions may lead to a point where some students may feel offended of their ethnic background or religious belief. Although Turkish movies were not shown to the group the students were offered to choose a Turkish film and analyze it for their term paper among over a hundred global films. However, as mentioned before the number is limited and only a few students chose to study a Turkish film.

The movies were chosen to provide an engaging medium in which to illustrate behavioral science concepts and supplement the knowledge that students receive from abstract behavioral science readings. The films aimed to raise questions about practically all key theoretical issues in the study of behavioral science.

The movies were screened over three two hour classes. The films were introduced with some background information on the context and questions were presented for later discussion. Following the screening students were asked to recall and comment on the film, on specific incidents and scenes where the main characters were confronted by choices they had to make. The discussions took place among the whole group. Watching a film is considered a pedogogical approach because there is attentive watching and questioning involved as a group in class. This approach also increases the retention level as the group goes through a collective learning experience (Brown, 2011). Watching a film with a group leads to a different type of discussion after the movie building up a collective experience that is educationally developmental.

In addition to the screenings in class the students were asked to choose a movie of their choice from a list of movies (Appendix B) with behavioral science content and write an essay relating the theoretical knowledge of the course with the movie.

\section{The Study}

\subsection{Purpose of the Study}

This study was conducted to evaluate the perceptions of management students learning behavioral science through movies. It focuses on the teaching approach through movies; its advantages, disadvantages, and limitations. 


\subsection{Context of the Study}

The study took place in one of the oldest established universities in Turkey. The department of business administration is under the "Faculty of Political Sciences" which was established 154 years ago. Therefore, the faculty is known for their dedication to its long lived traditions. All courses with an exception of few are in Turkish. Based on the informal assessment gathered from the students they do not watch any movies in other courses prior to this class. Only one they mentioned is they watched a documentary in their "Introduction to Management" course in the fall semester. But as noted by Brown (2011) in documentary the story is didactic and is aimed at convincing an already converted or on-side audience that watching tends to confirm an understanding rather than opening up discussion and further questioning.

\subsection{Participants}

Eighty five freshman business students who were enrolled in the mandatory behavioral science course were the participants of the study. Hundred and sixteen students were enrolled in the course however, only 85 of them responded to the survey.

Another participant of this research was the instructor of the behavioral science course. The instructor's observations and reflections of the course contributed to the findings of the study as well.

\section{Data Collection}

In spring 2012 the students who were in behavioral science course were asked to complete a survey at the end of the semester. Completing the survey was voluntary.

\subsection{Questionnaire}

The survey consisted of ten questions (see Appendix A). One of the questions asked demographic information such as gender and age of the students. Six questions used likert scale items. One question was a bi-polar question (yes/no) on trying to understand whether the behavioral science course helped the students to understand some aspects in the news or newspapers regarding sociological or social psychological issues that were discussed in their class. The students were asked to comment on any additional insights regarding their perceptions and concerns about using movies as a mode of learning at the end of the survey.

The survey was administered in Turkish language. This also reflects the primary medium of instruction at the department which is in Turkish. The students' comments that are shared in this study have been translated into English.

\section{Data Analysis}

Students' answers were analyzed using qualitative and quantitative analysis in order to gain knowledge regarding the students' preceptions towards teaching the behavioral science course through movies. Descriptive statistics were used to analyze the quantitative data reporting the frequencies of each survey item. The qualitative data which consisted of open-ended questions were analyzed using thematic analysis. Primary themes have emerged from the common responses of the students to the open ended survey questions. Within the data common themes that were related to the overall experience of how films enhanced the students' learning were grouped together.

\section{Findings}

Findings of the quantitative and qualitative data analysis is presented in this section. First, the results of the survey which focuses on the quantitative data is shared. Second, the common themes that emerged from the qualitative data are discussed.

Out of 85 participants who completed the survey, 25 were female and 60 were male. This ratio is also an indication of students' gender distribution in the business administration department.

Seventy-three (85.9\%) students thought watching movies in learning the concepts and theories of behavioral science to be very useful, while $11(12.9 \%)$ students indicated that they found it somewhat useful. Only one respondent did not find the movies useful at all. Meanwhile the students were asked to rate the three teaching methods used in the course in learning the concepts and theories of behavioral science that are (1) listening to the lecture, (2) class discussions and (3) watching a movie. Fifty-one (60\%) students indicated that listening to the lecture was very useful where $30(35.5 \%)$ students noted it to be somewhat useful and only $4(4.7 \%)$ thought is was not useful. Fifty-five students stated that class discussions were very useful, 29 (34.1\%) indicated that discussions were somewhat useful and only $1(1.2 \%)$ student noted that it was not very useful. Sixty-eight ( $80 \%)$ rated watching movies as a teaching method to be very useful where $15(17.6 \%)$ students indicated to be somewhat useful where one students noted as not useful at all. 
One of the questions in the survey aimed to find out whether the students developed a critical perspective of prejudices/attitudes after learning these themes in the behavioral science course or not. Fifty-eight (68.2\%) students noted that they have, where $25(29.4 \%)$ students indicated somewhat and only $2(2.4 \%)$ students claimed that they not have developed a critical perspective.

The participants were asked whether watching movies in class aroused their interest in studies related to behavioral science. Fifty-one (60\%) respondents said that they were very much interested where 28 answered as somewhat interested. Only $5(5.9 \%)$ respondents indicated that watching a movie did not arouse their interest where one student responded as his/her interest was not aroused at all.

Another question was to understand whether the students paid more attention to the newspaper articles, TV news, programs and discussions in their social environment about issues on attitudes, prejudices and cultural differences after taking the behavioral science course. Eighty-one respondents stated 'yes' and only 4 (4.7\%) answered 'no'. Clearly the students were able to follow the real life activities and paid attention to the issues discussed in class.

Forty-five (52.9\%) students indicated that watching movies which is a different teaching method compared to their other courses made the behavioral science class very interesting. Thirty-five $(41.2 \%)$ noted it to be somewhat interesting where 5 students did not find the teaching through movies method interesting at all.

The students were asked to rate the behavioral science course comparing it to the other courses they took the same semester. Twenty-nine (34.1\%) respondents noted that it was very interesting where $54(63.5 \%)$ indicated it to be somewhat interesting and $2(2.4 \%)$ respondents did not think it was an interesting course after all.

In addition, the following themes and issues emerged from the data analysis. The themes include, students: 1) ideas on teaching through movies 2) views on learning concepts and theories through movies 3) views on class discussions 4) views of critical thinking on their social environment.

\subsection{Ideas on Teaching through Movies}

A large number of students found teaching through movies methodology to be different than traditional lectures and supported the use of learning through movies. They found it to be entertaining and interesting that the level of retention is very high which is expected as the visual media is a central part of their lives. Students enjoy watching films because of the popularity of the medium in the current culture. Some of the students expressed:

The course was much more interesting than a traditional lecturing class. I did not want to miss a class. Not just listening but seeing made all the difference.

Reading the course book and articles were interesting enough. However watching a life-like movie helped me understand a lot of things that were blur in my mind. I could relate it to real life and it gave me a deeper understanding.

The course was just another traditional lecturing course for me until we started watching the movies. After the first movie analysis and discussion in class, I started reading extra material about the topics.

Watching the movies definitely helped me remember. I hardly remember anything from my other courses because they were all based on lecturing the theories. I could say I remember ninety percent of the things taught in this class and the movies were the main reason. I still remember why Derek (from American History X) became a racist and how his attitude changed.

We watch movies for entertainment and having a course that we watch movies and learn is the ultimate experience. How better can it get?

I never thought such a hard course based on a lot theories and concepts could be so much fun and entertaining. I learned so much.

The students not only learned about various behavioral science concepts but also learned how to see the concepts in different conceptual settings.

\subsection{Views on Learning Concepts and Theories through Movies}

Many students acknowledged that watching the movies illustrated difficult concepts and theories in the behavioral science course and helped them understand better. The results prove that movies have particularly good potential in teaching students certain concepts and theories and the method of film provide instructors a useful aid in reaching educational goals. Below are the statements made by some students explaining this:

Watching TV or reading the newspaper I could interpret certain events based on this course. I try to observe people's behavior and try to understand why he/she is acting like that. The movie analysis term paper was a great 
opportunity for me to apply all the concepts I learned in class.

I remember everything about the concepts and theories discussed in class because I remember the movies. You forget "words", but "seeing" something and learning from it gets stuck in your head, you always remember.

I loved the movies. They helped me understand all the theories and concepts that seemed to be "abstract". I thought I understood "stereotyping" till I watched the movies. The movies helped me understand the concepts at a new level.

Das Experiment was very interesting since it was a real experiment. American History X was shocking and Crash was an eye opening movie. After this course I started watching movies reflecting on the concepts we learned in class. My favorite movie is The Matrix and I used to think it was a great action movie. Now I know that there are so many social psychological concepts embedded that I love it even more.

If it wasn't for the movies I don't think I would have written such a good term paper and exam. The movies helped me to learn all the theories and concepts so well I don't think I would have learned so much just through lecturing.

In each movie there were a hundred pages worth of concepts and theories that we discussed in class. Since we watched four movies (three in class and one for our term paper) that makes a total of four hundred pages of our class book and I remember everything.

The films enable the students to see the concepts repeatedly in multiple contextual settings. The students reflections shows us that the approach of showing films to learn concepts allows them to learn more effectively because of the visual aspect of applying the course concepts and theories.

\subsection{Views on Class Discussions}

The discussion phase is very important in the behavioral science course. Students express their thoughts and opinions on many concepts and they are exposed to different ways of thinking. Movies dramatize and enlarge theoretical issues in ways that clarify and promote discussion. Most students acknowledged the merits of class discussions held in class and found it to be very useful. Some students expressed their views as:

I understood that all the issues we have been discussing in class are in all societies around the world. I kept asking myself on the topic of prejudices and stereotyping, whether I have any. I understood that a society's past/history affects a lot of the people's values and reflect on their attitudes and behaviors. I learned so much!

Regardless of people from different countries I learned that even in the same class we have different views on many things regarding the values that we share. The class discussions were so interesting to find out about the differences even among my classmates.

I'm politically a very active person and the discussions in class helped me understand different views on many concepts coming from my classmates that are from all over Turkey. I was amazed to hear about different views on abortion. I used to think, if someone is studying at a very well-known prestigious university they would have a different opinion than a farmer in a rural area. Well, seems that is not the case. People grow learning things and it is hard to change them even if they go to Mars.

Discussions in class proved that Turkish people have very strong prejudices and attitudes. Surprisingly I found out that I am one of them. I often found myself arguing with my friends after class on certain topics trying to convince them that I'm right!

One of the most disturbing class discussions we had was on the Kitty Genovese Syndrome where a young girl in NY was stabbed to death returning to her home at 3 am in the morning. Some boys in class said "if she returns home so late she brought it upon her". I'm still arguing with those boys.

Students became more active in their participation after they became familiar with the approach of the course. Most students commented on their personal observations regarding the topics and the level of participation as well as personal reflections was high throughout the semester.

\subsection{Views of Critical Thinking on Their Social Environment}

The intention of using movies is to help students examine important concepts and theories of behavioral science through the film and in doing so develop a critical perspective on those issues. Most students after the course stated that they were able to understand different human behavior in the society they lived in. Instead of judging whether the attitude is right or wrong they tried to develop an understanding of why people thought or behaved differently than they did. The movies helped them go through a empathetic identification. Some stated:

I try not to judge people anymore, or stereotype them. I understand that people behave according to what they 
have learned. This affects their attitudes. I understand the values embedded in the Turkish culture. If a young man tends to restrict his girlfriend's freedom, he probably learned the attitude from his father, doing the same to his mother.

I now have a new perspective on people. As a person who was brought up in a small town, this course changed my view on many aspects. I used to hate people that supported a different political party than mine but now I understand that they support their political party for the same reasons that I do.

I just read in the newspaper today about a rape victim. I now know that "rape" is a violent form of attack that a person cannot suppress. I felt so sorry for the victim but tried to understand why the rapist did such a thing and whether his inner circle of family and friends never realized his violence potential.

Even if I can't change others perceptions and attitudes, I definitely am working on my own. I did not know I was raised with such prejudices. I did not know I was stereotyping people from where they came from even in my own country. This course helped my so much understanding the society I live in.

I think this course should be taught to all departments because everyone in the future will be dealing with people. It important to understand about human behavior in a society especially the one you're living in. It helps you to develop a critical thinking on many things that you used to take for granted.

I was not aware of the social psychological problems in Turkey till this class. I question a lot things and try to understand why a lot things happen in our society. I wish I could prevent domestic violence occasions that bother me the most.

The films not only helped the students to understand social concepts but helped them towards having a critical perspective on human behavior in a social context. They were able to question the concepts to real life cases and acquire an understanding for the frameworks and concepts in practical terms.

\section{Discussion}

The aim of this study was to determine whether teaching through movies, which is a different format than traditional lecturing, for teaching a behavioral science course is an effective way to help students learn behavioral science concepts and theories or not. The study indicated that most students thought watching movies to be very useful and they enjoyed the class very much. Although students highly indicated that they learned a lot from the lectures, the class discussions and movies contributed to their learning and retention immensely. The findings clearly indicate that showing movies had the largest impact, compared to lectures and class discussions in learning concepts and theories. This result is expected as most students have grown up with visual media as a central part of their lives. Showing films enhance the connection with students in the classroom and illustrate concepts that may be difficult for some students to understand in behavioral science. Moreover, students' comments indicated that they found the theories and concepts easier to understand through the films.

One of the interesting findings was that most of the students developed a critical perspective on human behavior. Apart from learning concepts and theories it is important that the student is able to attain a critical thinking level and question real life situations. The movies screened in class and the discussions following them helped to attain this goal. The movies helped the students to connect with the lives and stories of everyday people and films represent those lives in rich detail creating a bridge of understanding and solidarity. The films assisted the students to ask questions and re-evaluate on what they know or how they think about the world. The majority of the students started to pay attention to the newspaper articles, TV news, programs and discussions in their social environment about issues discussed in class.

Student feedback confirmed the value of watching movies as a group was very eye opening. Class discussions enable them to learn from each other where the films served as a catalyst for their learning. Each student brought a different perspective that led to a better understanding of the theories and applied concepts of the film.

The class was very interactive and I loved the discussions in class. I was amazed and surprised by my classmates' comments. It helped me understand that we all have a different point of view and our families, our past all contribute to who we are.

The students' term project, choosing a film of their choice not only tested their knowledge of behavioral science concepts but gave them the opportunity to apply the concepts in a contextual setting of their choice. Some students complained that their choice of film hardly had any concepts to apply and wished they picked a better film for their project.

The faculty strongly suggests taking attendance in all classes but it is not mandatory. An instructor has the right to fail a student if he/she does not attend $70 \%$ of the classes. Although the instructor did not take attendance by 
name, she counted the number of students who attended the class every week. Absenteeism was very low as each week more than a hundred students were present in class. Students came to class not because of attendance but because they did not want to miss it. Most students indicated that watching movies in class aroused their interest in the course. Two students stated:

This was the only class I never skipped. And what's funny is that the instructor never takes attendance. I usually skip my other classes to the amount that I do not fail. This clearly proves that I loved the class and enjoyed it very much.

Although the course started at 8.30 and continued for three hours, I never missed a class. I tried not to stay up so late the previous evening so I could wake up early and catch the class. Although I hate early morning classes I loved the behavioral science course and didn't want to miss a minute of it.

The results clearly supported findings from Smith's 1968 research, that showing movies in class scored a higher interest in the course that resulted in lower absenteeism from class meetings. The evaluation comments reflected the students' belief that this approach allowed them to learn more efficiently because of the visual aspect of applying course concepts.

\section{Conclusion}

Studies have provided valuable information that using film in the classroom has advantages (Harper \& Rogers, 1999; Higgins \& Dermer, 2001; Parker, 2009). Especially when teaching behavioral science, films are useful to teach concepts and theories of human behavior and for exploring the dynamic complexities of the human behavior within the society they live in.

This research, teaching behavioral science through movies, points out showing films in the class make concepts and theories easier for students to understand. Students very much enjoyed watching films in class and learned a lot from their classmates in class discussions following the film. They preferred watching a film in class rather than just a traditional lecture or additional reading material.

While there are limitations to the small sample size of the study, it still provides valuable information on the process at work here in this field. This study can enhance business education and bring a value to the learning experience of the new generation of business students that have grown up with computers and television as an important aspect of their lives and are generally good at dealing with visual material. As Parker (2009) notes "with the changing environment of higher education, utilizing all means to include students in the learning process must be considered and taken advantage of to provide students with the best possible learning experience." (p.133). By integrating films into the behavioral science class students were able to retain interest in the course material.

Furthermore, giving a term project where the students choose a film of their own choice to analyze the concepts and theories of behavioral science successfully reinforced the students' ability to apply course concepts in various contextual settings. The responses of students and the research findings indicate that this approach is successful. One other important fact that needed to be addressed was whether teaching movies had an impact on critical thinking. The findings show that movies help the students to build critical perspectives on subjects with social context.

Although the literature suggests many benefits of showing movies in the classroom, it would be fair to mention some disadvantages. Kennedy, Senses, and Ayan (2009) experienced some students not liking the movie shown in class and mentioning that they hated it. When a student does not like a film it is possible that they will end up not relating the movie to the concepts and theories that they have learned in class. However, in this study, no student mentioned any comment on disliking the movies. It is important to address the students on which concepts and theories are expected to be analyzed and that while watching the movies to pay attention to the important issues at hand. One other disadvantage is certain parts of movies may not contribute to the understanding of the issue at large and movies usually have irrelevant material in the storyline. For example in the film Das Experiment, there was a love story integrated in the movie that is totally irrelevant with the Stanfords Prison Experiment. However it must be emphasized that movies are different than documentaries, that they have a storyline and plot, and most important of all they were not produced for teaching material.

Using the exploratory approach this study attempted to identify teaching through movies in a behavioral science course with business administration students. The findings highlight that the movies helped the students to develop interest in the behavioral science field. While there are limitations to the small sample size of the study, it is hoped that this study encourages instructors to use movies in other business courses in the future as well as other future research studies. Expanding the sample of the students as well as the context of the study would help 
to support the existing findings and give opportunity to new research studies to expand the data analysis to other significant variables that can explain the perceived effectiveness of teaching through films in different student groups.

As the film critic Roger Ebert states "The movies come closer than any other art form in giving us the experience of walking in someone else's shoes, they allow us an opportunity to experience what it would be like to live within another gender, race, religion, nationality, or period of time. They expand us, they improve us, and sometimes they ennoble us."

\section{References}

Anwary, A. (2003, October). Teaching about South Asian women through film. Teaching Sociology, 4(31), 428-440. http://dx.doi.org/10.2307/3211367

Atherton, M. (2013). Teaching through film: Utilizing popular criminology in the classroom. Journal on Excellence in College Teaching, 24(2), 77-99.

Baccarani, C., \& Brunetti, F. (2002). The use of movies in management education since "life is like a box of chocolates. You never know what you're gonna get". Selected papers from the 13th International Conference on College Teaching and Learning, 7-26.

Bluestone, C. (2000). Feature films as a teaching tool. College Teaching, 48(4), 141-146. http://dx.doi.org/10.1080/87567550009595832

Brown, T. (2011). Using film in teaching and learning about changing societies. International Journal of Life Long Education, 30(2), 233-247. http://dx.doi.org/10.1080/02601370.2010.547615

Chang, T. F. H., \& Cryer, M. T. (2009). Popcorn and politics: Teaching politics through film. Labor Studies Journal, 34(3), 408-414. http://dx.doi.org/10.1177/0160449X08322764

Considine, D. M., \& Baker, F. (2006). Focus on film: Learning it through movies. Middle Ground, 10(2), 12-15.

Engert, S., \& Spencer, A. (2009). International relations at the movies: Teaching and learning about international politics through film. Perspectives, 17(1), 83-103.

Ganz, M. (2006). Organizing: People, power and change. Harvard: Harvard University Press.

Gioia, D. A., \& Brass, D. J. (1985). Teaching the TV generation: The case for observational learning. Organizational Behavior Teaching Review, 10(2), 11-18.

Gregg, V. R, Hosley, C. H., Weng, A., \& Montemayor, R. (1995). Using films to remote active learning in the college classroom. Proceeding of the Annual Conference on Undergraduate Teaching of Psychology, 32-43. Ellenville, NY.

Harper, R. E., \& Rogers, L. E. (1999). Using feature films to teach human development concepts. Journal of Humanistic Counseling, Education \& $\quad$ Development, $\quad 38(2), \quad 89-97$. http://dx.doi.org/10.1002/j.2164-490X.1999.tb00067.x

Higgins, J. A., \& Dermer, S. (2001). The use of film in marriage and family counselor education. Counselor Education and Supervision, 40(3), 182-192. http://dx.doi.org/10.1002/j.1556-6978.2001.tb01251.x

Hooks, B. (2008). Reel to real: Race, sex, and class at the movies. New York: Routledge.

Hunt, C. S. (2001). Must see TV: The timeliness of television as a teaching tool. Journal of Management Education, 25, 631-647. http://dx.doi.org/10.1177/105256290102500603

Johnston, C. (2001). Movies are the key to lively lectures. Times Higher Education Supplement, $1945,13$.

Kennedy, N. F., Senses, N., \& Ayan, P. (2011). Grasping the social through movies. Teaching in Higher Education, 16(1), 1-14. http://dx.doi.org/10.1080/13562517.2010.507305

Nussbaum, M. (1997). Cultivating Humanity: A classical defense of reform in liberal education. Cambridge: Harvard University Press.

Paddock, J. R., Terranova, S., \& Giles, L. (2001). SASB goes Hollywood: Teaching personality theories through movies. Teaching of Psychology, 28(2), 117-121. http://dx.doi.org/10.1207/S15328023TOP2802_11

Parker, R. D. (2009). Watch this clip: Using film as an augmentation to lecture and class discussion. Academy of Educational Leadership Journal, 13(4), 129-134.

Rubin, L., \& Herbert, C. (1998). Model for active learning: Collaborative peer teaching. College Teaching, 46(1), 26-30. http://dx.doi.org/10.1080/87567559809596229

Smith, D. D. (1982). Teaching undergraduate sociology through feature films. Teaching Sociology, 10(1), 98-101. http://dx.doi.org/10.2307/1316999

Smith, G. W. (2009). Using feature films as the primary instructional medium to teach organizational behavior. Journal of Management Education, 33(4), 462-489. http://dx.doi.org/10.1177/1052562909335861

Tognozzi, E. (2010). Teaching and evaluating language and culture through film. Italica, 87(1), 69-91. 


\section{Appendix A}

\section{Student Survey}

1. Please state:

Age:

Gender: Female ( ) Male ( )

Hometown:

2. In learning the concepts and theories (prejudice, attitudes) of Behavioral Science, the movies that I watched have been

() Very useful

( ) Somewhat useful

( ) Not very useful

( ) Not useful at all

3. In learning the concepts and theories of Behavioral Science I rate the following teaching methods as:

very useful Not useful at all

Very useful

Somewhat useful

Not

Listening to the lecture

( )

( )

( )

( )

( )

( )
( )

( )

()

Watching a movie

( )

( )

4. I believe I have developed a critical perspective of prejudice/attitudes after learning these themes in my Behavioral Science course.

() Very

( ) Somewhat

() Not very

() Not at all

5. Watching movies in class aroused my interest in studies related to Behavioral Science.

() Very

( ) Somewhat

( ) Not very

() Not at all

6. After taking the Behavioral Science course, I started paying more attention to the newspaper articles, TV news, programs and discussions in my social environment about issues on attitudes, prejudices and cultural differences.

( ) Yes

( ) No

7. Watching movies in the Behavioral Science course made me more interested in this discipline.

() Very

( ) Somewhat

( ) Not very

() Not at all

8. If I rate all the courses I took this semester from the most interesting to the least interesting, the Behavioral Science course will be rated as:

( ) Very interesting

() Somewhat interesting

( ) Not very interesting

( ) Not interesting at all 
9. What are your personal opinions about watching movies in the Behavioral Science course? To what extent have they contributed to you in learning the concepts and theories?

10. Did the concepts and theories discussed in the Behavioral Science course help you understand the sociological and social psychological issues and problems in Turkey? In what way?

Please feel free to comment on anything related to the course.

\section{Appendix B}

\section{Non-Turkish Movies}

12 Monkeys (1995), A Time to Kill (1996), About Schmidt (2002), Blindness (2008), Blood Diamond (2006), Breaking the Waves (1996), Cinema Paradiso (1988), Dead Poets Society (1989), Fargo (1996), Fight Club (1999), Forrest Gump (1994), Frida (2002), Fried Green Tomatoes (1991), Godfather (1972), Goodwill Hunting (1997), Insomnia (2002), House of Fogs (2003), Hotel Rwanda (2004), In the Bedroom (2001), In the Name of the Father (1993), Leon (1994), Lord of the Flies (1990), Magnolia (1999), Match Point (2005), Monster's Ball (2001), Patch Adams (1998), Philadelphia (1993), Saving Private Ryan (1998), Schindler's List (1993), Seven (1995), Shine (1996), The Color Purple (1985), The Cider House Rules (1999), The Elephant Man (1980), The Fisher King (1991), The Insider (1999), The Kite Runner (2007), To Kill a Mockingbird (1962), White Oleander (2002)

Turkish movies

Mutluluk - Bliss (2007)

Güneşi Gördüm - I Saw the Sun (2009)

Güle Güle-Farewell (2000)

Takva (2006)

Sürü - Herd (1979)

Yol - The Road (1982)

Babam ve Oğlum -My Father and Son (2005)

Duvara Karşı -Head On (2004)

Başka Dilde Aşk - Love in Another Language (2009)

Büyük Adam Küçük Aşk (2001)

\section{Copyrights}

Copyright for this article is retained by the author(s), with first publication rights granted to the journal.

This is an open-access article distributed under the terms and conditions of the Creative Commons Attribution license (http://creativecommons.org/licenses/by/3.0/). 